magnetic resonance enterography (MRE), barium study (BS), CRP and clinical assessment (CA).

Results Seventy-one patients (44 female; median age at diagnosis 24 years) were included with a median duration of IBD prior to antiTNF of 24 (0-264) months. Indications were severe active luminal (50/71), fistulating perianal $(18 / 71)$ and other fistulating disease $(3 / 71)$. The median treatment duration was 18 months (range $12-78)$ with 62 (87\%) on immunomodulators post anti-TNF withdrawal. Relapse rates within 90,180 and 365 days were $3 / 71(4.2 \%$ ), $14 / 67(21 \%)$ and $27 / 57(47 \%)$ respectively. In perianal disease alone, the relapse rate was $6 / 18(33 \%)$ at 1 year. 25 of those who relapsed were retreated with anti-TNF, with an overall recapture rate of $84 \%$. In those retreated with the same agent as previously withdrawn the response rate was $80 \%$. A further 5 were successfully retreated with ADA when IFX had been withdrawn. Those (6) who had a dose escalation in 6 months prior to withdrawal all relapsed.

Assessment practise changed following NICE guidance in 2010. Prior to this 5/15(33\%) stopping anti-TNF had a CA alone. Following NICE guidance $2 / 56$ (3.6\%) were assessed only by CA. Investigations to complement routine CA by Harvey Bradshaw Index (HBI), included $\geq 1$ of colonoscopy (52), CC (4), MRE (19), SBC (5), BS (2) and CRP (66). $\mathrm{HBI} \geq 4$ and a CRP of $\geq 5$ in the 6 months prior to formal assessment was observed in 26 patients. 14/26 (54\%) relapsed following cessation of anti-TNF (positive predictive value of $61 \%$ ). Further invasive investigations in this group were abnormal in 2 patients.

Conclusion In this UK cohort, elective withdrawal of anti-TNF was associated with a relapse rate of $48 \%$ after 12 months, with a high retreatment response rate. Due to NICE guidance, increased invasive assessment occurred, but the role of endoscopy and imaging to evaluate remission prior to withdrawal of anti-TNF needs further evaluation.

Disclosure of Interest A. Brooks: None Declared, S. Sebastian Conflict with: Dr Sebastian has participated in advisory boards and received speakers honoraria, educational and research grants from Abbott and MSD, K. Robinson: None Declared, L. Warren: None Declared, A. Wright: None Declared, A. Marsh: None Declared, H. Tsai Conflict with: Dr Tsai has participated in advisory boards and received speakers honoraria, educational and research grants from Abbott and MSD, F. Majeed: None Declared, M. McAlindon: None Declared, P. Hamlin Conflict with: Dr Hamlin has participated in advisory boards and received support for specialist nurses from Abbott and MSD, A. Lobo:None Declared

\section{PTU-055 LONG-TERM EFFICACY OF ADALIMUMAB FOR TREATMENT OF MODERATELY TO SEVERELY ACTIVE ULCERATIVE COLITIS}

doi:10.1136/gutjnl-2013-304907.147

1J-F Colombel, ${ }^{2} \mathrm{~W}$ J Sandborn, ${ }^{3} \mathrm{D}$ Wolf, ${ }^{4} \mathrm{R}$ Panaccione, ${ }^{5,} \mathrm{~A}$ Lazar, ${ }^{5} \mathrm{M}$ Kron, ${ }^{6} \mathrm{~A}$ M Robinson, ${ }^{6} \mathrm{R}$ Thakkar. 'Centre Hospitalier Universitaire de Lille, Lille, France; ${ }^{2}$ UCSD, La Jolla; ${ }^{3}$ Atlanta Gastro Assoc, Atlanta, United States; ${ }^{4}$ University of Calgary, Calgary, Canada; ${ }^{5} A b b V i e$ Deutschland, Ludwigshafen, Germany; ${ }^{6}$ AbbVie, North Chicago, United States
Introduction Objective To evaluate long-term efficacy of adalimumab (ADA) for patients with moderately to severely active ulcerative colitis (UC).

Methods The ADA UC development programme consists of two trials (ULTRA 1 and ULTRA 2) ${ }^{1,2}$ followed by an ongoing multicentre open-label $(\mathrm{OL})$ extension. Patients entering the extension on $\mathrm{OL}$ weekly ADA dosing continued on same. Patients entering the extension study from any blinded cohort (ADA or placebo [PBO]) or an OL cohort receiving ADA 40mg every other week (eow) received OL $\mathrm{ADA} 40 \mathrm{mg}$ eow. For patients entering from a blinded cohort, increase to $40 \mathrm{mg}$ weekly for flare or non-response was allowed at or after week 12. For patients entering from an OL cohort, increase to $40 \mathrm{mg}$ weekly for flare or non-response was allowed at or after week 12 for patients in clinical response at entry, or week 2 for patients with inadequate response at entry. Adjustments to concomitant medications including corticosteroids were allowed per protocol specifications. Partial Mayo score (PMS, Mayo score without endoscopy subscore) was collected at every study visit during the lead-in trials and the OL extension. Mean PMS over time through 3 years (172 weeks) from first dose of ADA was assessed using observed case method in the "any ADA" population (patients who received at least one dose of ADA in the lead-in or extension trials) using a data cut off of 16 December 2011. The proportion of patients in clinical remission per PMS (PMS $\leq 2$ with no subscore $>1$ ) at week 60 of the $\mathrm{OL}$ extension was assessed in the intent-to-treat (ITT) population (patients enrolled in the extension, excluding patients from sites non-compliant with good clinical practises), using non-responder imputation (NRI) to handle missing data.

Results The observed mean PMS at day of first dose of ADA was $5.9(\mathrm{~N}=992)$, and decreased over time through 172 weeks of treatment to $1.5(\mathrm{~N}=210$, Table). Of the 588 ITT patients from the leadin studies who enrolled into the OL extension, 325 (55.3\%, NRI) achieved clinical remission per PMS at week 60 of the OL extension. No new safety signals were observed.

Conclusion The results of the ongoing extension trial support clinically meaningful efficacy of adalimumab for the treatment of moderately to severely active UC, sustained for up to 3 years.

Disclosure of Interest J.-F. Colombel Shareholder of: Intestinal Biotech Development, Grant/Research Support from: AbbVie, Ferring, Merck \& Co, UCB Pharma, Giuliani SPA, Consultant for: AbbVie, Amgen, Biogen Idec Inc, Boehringer-Ingelheim, Inc., Bristol Meyers Squibb, Cellerix SL, Chemocentryx, Inc., Janssen, Cosmo Technologies, Ltd, Elan Pharmaceuticals, Inc., Roche, Giuliani SPA, Given Imaging, Glaxo Smith Kline, Immune Pharmaceuticals Ltd., ISR, Merck \& Co., Inc., Takeda, Neovacs SA, Ocerra Therapeutics, Inc., Pfizer Inc. Prometheus, Sanofi, Shire Pharmaceuticals, Synta Pharmaceutical Corporation, Takeda, Teva Pharmaceuticals, Therakos, TXcell, UCB Pharma, Speaker bureau with: AbbVie, Janssen, Falk Pharma, Ferring, Given Imaging, Merck \& Co., Inc., Shire Pharmaceuticals, UCB Pharma, W. Sandborn Grant/Research Support from: AbbVie, Bristol Meyers Squibb, Roche, Glaxo Smith Kline, Janssen, Takeda, Novartis, Pfizer, Procter and Gamble Pharmaceuticals, Shire

Abstract PTU-055 Table Mean PMS over time in the "any ADA" population, observed

\begin{tabular}{|l|c|c|c|c|c|c|c|c|c|c|c|c|}
\hline $\begin{array}{l}\text { Study } \\
\text { visit, } \\
\text { week }\end{array}$ & 0 & 4 & 8 & 16 & 32 & 52 & 64 & 88 & 112 & 136 & 160 & 172 \\
\hline $\mathrm{N}$ & 992 & 914 & 886 & 842 & 776 & 590 & 551 & 516 & 451 & 401 & 272 & 210 \\
\hline $\begin{array}{l}\text { PMS, } \\
\text { mean }\end{array}$ & 5.9 & 4.2 & 3.9 & 3.4 & 3.1 & 2.6 & 2.1 & 2.1 & 1.8 & 1.8 & 1.6 & 1.5 \\
\hline
\end{tabular}


Pharmaceuticals, and UCB Pharma, Consultant for: AbbVie, ActoGeniX NV, AGI Therapeutics, Inc., Alba Therapeutics Corporation, Albireo, Alfa Wasserman, Amgen, AM-Pharma BV, Anaphore, Astellas Pharma, Athersys, Inc., Atlantic Healthcare Limited, Aptalis, BioBalance Corporation, Boehringer-Ingelheim Inc, Bristol Meyers Squibb, Celgene, Celek Pharmaceuticals, Cellerix SL, Cerimon Pharmaceuticals, ChemoCentryx, CoMentis, Cosmo Technologies, Coronado Biosciences, Cytokine Pharmasciences, Eagle Pharmaceuticals, Eisai Medical Research Inc., Elan Pharmaceuticals, EnGene, Inc., Eli Lilly, Enteromedics, Exagen Diagnostics, Inc., Ferring Pharmaceuticals, Flexion Therapeutics, Inc., Funxional Therapeutics Limited, Genzyme Corporation, Roche, Gilead Sciences, Given Imaging, Glaxo Smith Kline, Human Genome Sciences, Ironwood Pharmaceuticals, Janssen, KaloBios Pharmaceuticals, Inc., Lexicon Pharmaceuticals, Lycera Corporation, Meda Pharmaceuticals, Merck Research Laboratories, Merck \& Co., MerckSerono, Takeda, Nisshin Kyorin Pharmaceuticals Co., Ltd., Novo Nordisk A/S, NPS Pharmaceuticals, Optimer Pharmaceuticals, Orexigen Therapeutics, Inc., PDL Biopharma, Pfizer, Procter and Gamble, Prometheus Laboratories, ProtAb Limited, Purgenesis Technologies, Inc., Receptos, Relypsa, Inc., Salient Pharmaceuticals, Salix Pharmaceuticals, Inc., Santarus, Shire Pharmaceuticals, Sigmoid Pharma Limited, Sirtris Pharmaceuticals, Inc. (a GSK company), S.L.A. Pharma (UK) Limited, Targacept, Teva Pharmaceuticals, Therakos, Zeria Pharmaceutical Co, TxCell SA, UCB Pharma, Viamet Pharmaceuticals, Vascular Biogenics Limited (VBL), Warner Chilcott UK Limited, Speaker bureau with: AbbVie, Bristol Meyers Squibb, and Janssen, D. Wolf Grant/Research Support from: AbbVie, BristolMyers Squibb, GIVEN Imaging, Janssen Biotech Inc, Takeda, Prometheus Laboratories, UCB Pharma, Consultant for: AbbVie, GIVEN Imaging, Janssen Biotech Inc, Takeda, Prometheus Laboratories, Salix Pharmaceuticals, UCB Pharma, Speaker bureau with: AbbVie, Janssen Biotech Inc, Prometheus Laboratories, UCB Pharma, Warner Chilcott, R. Panaccione Grant/Research Support from: AbbVie, Osiris Therapeutics, Inc, UCB, Inc, Consultant for: AbbVie, Axcan Pharma, Inc, Biogen/IDEC, Bristol-Myers Squibb, Janssen, Chemocentryx, Elan Pharmaceuticals, Inc., Ferring Pharmaceuticals, Inc., Roche, Novartis Pharmaceuticals, Inc., PDL Biopharma, Inc., UCB, Inc, Speaker bureau with: AbbVie, Janssen, Elan Pharmaceuticals, Inc., Medscape, A. Lazar Shareholder of: May own Abbott and/or AbbVie stock, Employee of: AbbVie, M. Kron Shareholder of: May own Abbott and/or AbbVie stock, Employee of: AbbVie, A. Robinson Shareholder of: May own Abbott and/or AbbVie stock, Employee of: AbbVie, R. Thakkar Shareholder of: May own Abbott and/or AbbVie stock, Employee of: AbbVie

\section{REFERENCES}

1. Reinisch. Gut. 2011; 60:780.

2. Sandborn. Gastroenterology. 2012; 142:257.

\section{PTU-056 PREGNANCY OUTCOMES IN PATIENTS WITH CROHN'S DISEASE: LESSONS FROM AUDIT IN A SPECIALIST IBD CLINIC}

doi:10.1136/gutjnl-2013-304907.148

1,2, A Koumi, ' $\mathrm{K}$ Taylor, ' $\mathrm{J}$ Duncan, 'S Anderson, 'P Irving, ' $\mathrm{C}$ P Nelson, ' J Sanderson. 'Guys and St Thomas's Hospital, London, UK; 2417, Army Share Fund Hospital, Athens, Greece

Introduction Crohn's disease (CD) affects mainly people in their reproductive years. Concerns regarding family planning are the impact of $\mathrm{CD}$ on fertility and course of pregnancy,transmission to the offspring,issues concerning drug safety,mode of delivery and congenital anomalies. Published data is reassuring but awareness of outcomes locally can provide data regarding possible additional benefit from specialist obstetric medicine service.

Methods Pregnant patients with CD were identified through the Electronic Patient Record System. Data were collected from
October 2008-November 2012.Further information on outcomes was gathered from individual consultation with patients.

Results 80 pregnancies in 57 patients with CD were identified.10 patients currently pregnant, 9 patients(13 pregnancies) with incomplete data were excluded.Therefore,pregnancy outcomes of 57 pregnancies/38 patients (mean age: 30.7 years) were analysed. $31 / 38(82 \%)$ of patients had luminal disease,7/38(18\%) perianal disease.36/38(95\%) conceived naturally,1/38(2.5\%) by assisted reproduction, $1 / 38(2.5 \%)$ by IVF. $25 / 57(44 \%)$ pregnancies were on no treatment in early pregnancy, $4 / 57(7 \%)$ on biologics [Infliximab 3/4(75\%),Adalimumab1/4(25\%)],6/57(10\%) on biologics $+\mathrm{t}$ hiopurines(TPN),6/57(10\%) on TPN,6/57(10\%) on TPN +5ASA,7/57(12\%) on 5-ASA, $2 / 57(3.5 \%)$ on steroids and $1 / 57(1.7 \%)$ on elemental diet.15/57(26\%) pregnancies had flares,of which $5 / 15(33 \%)$ continued throughout pregnancy.5/15(33\%) occurred in the 1 st trimester, $4 / 15(27 \%)$ in the $2 \mathrm{nd}, 1 / 15(7 \%)$ in the $3 \mathrm{rd}$. Of all pregnancies with flares, $9 / 15(60 \%)$ were on no CD therapy. The mean week of delivery was 39.5 weeks (36-42).32/46(70\%) of deliveries were vaginal and $14 / 46(30 \%)$ by Caesarian section (CS). Of CS,8/14(57\%) were planned due to perianal disease $5 / 8(63 \%)$ or obstetric indication $3 / 8(37 \%)$.Pregnancy outcomes were:live births 46/57(81\%), miscarriages $10 / 57(17 \%)$, termination $1 / 57(2 \%)$. The mean birth weight (BW) of the newborns was $3 \mathrm{~kg}$ $(1.9 \mathrm{~kg}-5.1 \mathrm{~kg}) .4 / 46(11 \%)$ of the babies were of low BW $(<2.5 \mathrm{~kg})$. Neonatal issues were recorded in $5 / 46(11 \%) ; 1$ diabetes mellitus, 2 cardiac anomalies, 1 with viral infection at 8 days, 1 cot death. Of the miscarriages, $5 / 10(50 \%)$ were on no CD therapy and $4 / 10(40 \%)$ flared in early pregnancy. The termination was due to use of medication unrelated to $\mathrm{CD}$ that could potentially cause congenital anomalies.

Conclusion The number of pregnancies in a specialist IBD clinic is high up to 20/year in this series highlighting a potential additional service need.A specialist obstetric medicine service can provide reassurance regarding safety of drugs in pregnancy,which in turn may reduce flare rates and result in good pregnancy outcomes. Observed outcomes did not fall outside that expected from larger reported series.

Disclosure of Interest None Declared

\section{PTU-057 POINT-OF-CONTACT FAECAL CALPROTECTIN (FC) TESTING IN DIARRHOEA HELPS DECISION MAKING FOR REFERRAL TO GASTROENTEROLOGISTS: A PRIMARY CARE PILOT STUDY IN NORTH EAST ENGLAND}

doi:10.1136/gutjnl-2013-304907.149

1.2, A Dhar, ${ }^{\prime} \mathrm{S} H \mathrm{H}$ Lee, ${ }^{3} \mathrm{H}$ Borthwick, ${ }^{4} \mathrm{P}$ Nair, ${ }^{4} \mathrm{C}$ White. ${ }^{1}$ Gastroenterology, County Durham \& Darlington NHS Foundation Trust, Bishop Auckland; '2School of Medicine and Health, Durham University, Stockton-on-Tees; ${ }^{3}$ Clinical Biochemistry, County Durham \& Darlington NHS Foundation Trust; "Primary Care, Durham and Dales Clinical Commissioning Group, Bishop Auckland, UK

Introduction Faecal Calprotectin (FC) is a cytosolic protein belonging to the S-100 family of calcium binding proteins found in neutrophils. It is excreted in the intestinal lumen in inflammatory conditions of the gut and can be used to distinguish irritable bowel syndrome (IBS) from other inflammatory bowel conditions such as colitis, diverticulosis, etc. Point-of-contact qualitative FC tests are now available and can be used in primary care to aid decision making for referrals to gastroenterologists for young patients presenting with chronic diarrhoea.

Methods Aims To assess the feasibility and cost effectiveness of a primary care Pathway using a point-of-contact FC Test (Caldetect ${ }^{\circledR}$ ) to aid decision making for referrals to gastroenterology in young patients presenting to their primary physicians with chronic diarrhoea. Methods: Primary Care data indicated that approximately 253 referrals are made annually to gastroenterologists from Primary Care to assess patients $<60$ years presenting with diarrhoea, costing 